\title{
Diagnosing the automobile starting system
}

This article presents a new method for analysing the torque of an internal combustion engine using registered electromechanical runs and magnetic field distribution in a starter. The aim of the study was to develop a model of the starting current of an internal combustion engine and carry out verification tests on real objects. The developed model allows to simulate the shutdown of individual cylinders. Experimental research was conducted using the Bosch FSA 740 equipment for four internal combustion engines under variable operating conditions. During testing, the starting current and relative compression in cylinders were recorded. Simulating the variable load of the starter, the magnetic induction distribution of the magnetic induction was recorded in the feed slot. The research will be used to develop a method of diagnosing the starter and determining the torque of the internal combustion engine.

Key words: starter, starting current, diagnostics, Matlab, engine torque

\section{Introduction}

Because of the growing environmental requirements of the automotive industry, a lot of attention is paid to maintaining the engine and its equipment in proper technical condition, guaranteeing air pollution as low as possible. In addition, new technical solutions are introduced to reduce emissions. In the case of the starter system, it is commonly used in new vehicles with a start-stop system that reduces fuel consumption and the emission of toxic components into the environment, while increasing the number of starter starts by $50 \%$.

The starting system is the only device in the vehicle that is not monitored as a pilot light or information on the onboard computer. Damage to it affects the ecology in terms of the start-up phase and passenger safety when the engine is stopped $[4,5]$. It is therefore desirable to develop models and diagnostic patterns that allow the in-service supervision of the starting system.

A frequent damage to starters is the wear of brushes and bushes. In the works $[1,7,8]$, the authors attempted to diagnose the boot system using neural networks. The results confirm the possibility of diagnosing the condition of the starter brushes using a single-directional neural network. In reference [2] a wear model of the starter bearing system is developed. This model can be used to describe and interpret the actual operating processes as well as evaluate the durability of the starter bearings. The vibroacoustic studies of the starter [6] have confirmed the possibility of using a vibroacoustic signal to assess the technical condition of the pacemaker. Work [9] analyses the effect of engine torque variations on the engine startup process using electric and pneumatic starters. The relationship between the momentary torque values and the crankshaft rotational speed was determined. It has been found that the degree of nonuniformity of instantaneous speed is dependent on the value of the torque component of the number of engine cylinders and the power of the starting system.

\section{Analysis of engine torque}

Movement resistance associated with the operation of the internal combustion engine significantly limits its technical indicators. When calculating the torque moments of the internal combustion engine, the resistance torque generated by the individual engine functionalities must be taken into account.

The total anti-torque of the motor can be represented by the pattern:

$$
M_{\mathrm{a}-\mathrm{t}}=\mathrm{M}_{\mathrm{f}}+\mathrm{M}_{\mathrm{g}}+\mathrm{M}_{\mathrm{i}}+\mathrm{M}_{\mathrm{aux}}
$$

adding up the moment values of: $\mathbf{M}_{\mathrm{f}}-$ friction, $\mathbf{M}_{\mathrm{g}}-$ gas forces, $M_{i}$ - inertia forces of the internal combustion engine, $\mathrm{M}_{\mathrm{aux}}$ - auxiliary devices.

An important component of the torque is the friction torque $\mathrm{M}_{\mathrm{f}}$, resulting from the frictional forces accompanying the engine, including the piston travel and the rings mounted on the cylinder liners, as well as the frictional forces associated with the pivot movement with respect to the pan in the main and the main bearing.

The moment of friction can be expressed as:

$$
\mathrm{M}_{\mathrm{f}}=\frac{\mathrm{v}_{\mathrm{e}}}{4 \pi \cdot \mathrm{p}_{\mathrm{f}}}
$$

$\mathrm{V}_{\mathrm{e}}$ - engine displacement, $\mathrm{p}_{\mathrm{f}}$ - friction force acting on the piston with respect to the surface unit.

Variability of the torque during one engine cycle is due to the compression of the load in the individual cylinders and is caused by the gas pressure acting on the surface of the piston crown, connecting rod bearings and the main crankshaft bearings. Changes in resistance torque values from gas forces follow the formula:

$$
\begin{gathered}
\mathrm{M}_{\mathrm{g}}(\alpha)=-\operatorname{Sr}\left(\sin \varphi+\frac{\lambda \sin \varphi+\mu \cos \varphi}{\sqrt{1-(\lambda \sin \varphi+\mu)^{2}}}\right) \\
\left(\mathrm{p}_{1}(\alpha)+\mathrm{p}_{2}(\alpha+2 \pi)+\mathrm{p}_{3}(\alpha+3 \pi)+\mathrm{p}_{4}(\alpha+4 \pi)-4 \mathrm{p}_{0}\right)
\end{gathered}
$$

$\mathrm{S}-$ piston head surface area, $\mathrm{r}-$ crankshaft crank radius, $\varphi$ - angle of rotation of the crankshaft, $p_{i}(I=1,2,3,4)$ - instantaneous pressure in individual cylinders, $\mathrm{p}_{0}-$ ambient pressure.

Coefficients:

$$
\mu=\frac{\mathrm{e}}{\mathrm{l}} \quad \lambda=\frac{\mathrm{r}}{\mathrm{l}}
$$

e - mischievousness, 1 - length of connecting rod, $r-$ connecting rod radius. 
The moment of inertia, which accompanies changes in engine speed, also has a significant effect on the resistance of the engine. The moment of inertia of the internal combustion engine can be represented by the formula:

$$
\frac{\mathrm{I} \omega_{\mathrm{r}}^{2}}{2}=\frac{\mathrm{I}_{\mathrm{r}} \omega_{\mathrm{r}}^{2}}{2}+\frac{\mathrm{I}_{\mathrm{zr}} \omega_{\mathrm{r}}^{2}}{2}+\frac{2 \mathrm{~m}_{\mathrm{t}} \mathrm{V}_{\mathrm{t}}^{2}}{2}+\frac{2 \mathrm{~m}_{\mathrm{k}} \mathrm{V}_{\mathrm{k}}^{2}}{2}+\frac{\mathrm{I}_{\mathrm{b}} \omega_{\mathrm{k}}^{2}}{2}
$$

$\mathrm{I}$ - torque reduced to the axis of the starter rotor, $\mathrm{I}_{\mathrm{zr}}-$ moment of inertia of the rotary masses of the internal combustion engine reduced to the axis of the crankshaft, $\mathrm{I}_{\mathrm{b}}-$ moment of inertia of the connecting rod relative to the axis passing through the centre of gravity and perpendicular to the connecting rod plane, $\mathrm{I}_{\mathrm{r}}$ - moment of inertia of the starter, $m_{t}-$ mass of the piston and the piston pin, $m_{k}-$ mass of the connecting rod, $\mathrm{V}_{\mathrm{k}}$ - instantaneous linear velocity of the centre of gravity of the connecting rod, $\omega_{k}$ - instantaneous angular velocity of the connecting rod, $\mathrm{V}_{\mathrm{t}}-$ instantaneous linear velocity of the piston, $\omega$ - angular velocity of the crankshaft, $\omega_{\mathrm{r}}-$ angular velocity of the starter

At the moment of resistance there is also the moment resulting from the work of auxiliary equipment, necessary for the proper functioning of the engine: cooling, lubrication and fuel systems. In order for auxiliaries to function, they must be supplied with sufficient energy. During normal operation of the engine, this energy reduces the available power of the engine, while the start-up of the engine must be provided by the start-up system, which must balance it, and the excess power generated by the engine is expected to result in effective movement. Calculations based on empiric engine attachments relate to established operating conditions (temperature and load), their use for startup conditions may be misleading because of differences in the assumptions for which they were designated.

The moment of the auxiliary devices can be represented by the formula:

$$
\mathrm{M}_{\mathrm{UP}}=\mathrm{M}_{\mathrm{wp}}+\mathrm{M}_{\mathrm{op}}+\mathrm{M}_{\mathrm{inj}}+\mathrm{M}_{\mathrm{al}}+\mathrm{M}_{\mathrm{ca}}+\mathrm{M}_{\mathrm{opr}}
$$

where $M$ is, respectively, the moment of: $M_{w p}$ - the water pump, $\mathbf{M}_{\mathrm{op}}$ - the oil pump, $\mathbf{M}_{\mathrm{w}}$ - the injection pump, $\mathbf{M}_{\mathrm{al}}-$ the alternator resistance, $\mathbf{M}_{\mathrm{sk}}-$ the compressor air, $\mathrm{M}_{\mathrm{pow}}-$ the oil pump resistance.

The tangential forces for different motor states are shown in Figures 1-3.

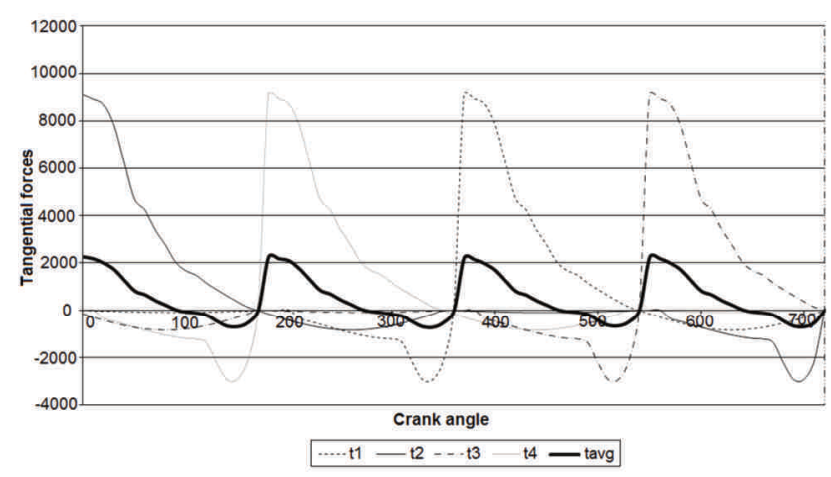

Fig. 1. Crank tangential forces in a smooth-running motor

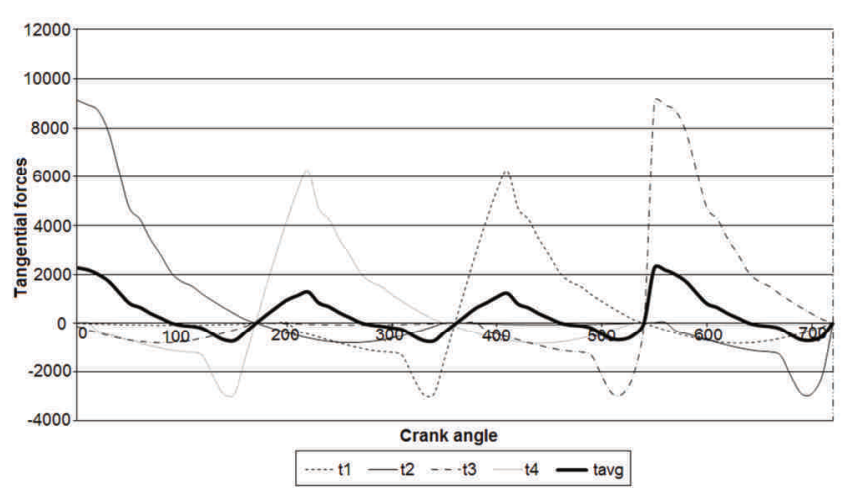

Fig. 2. Crank pin effort - no burning in two cylinders

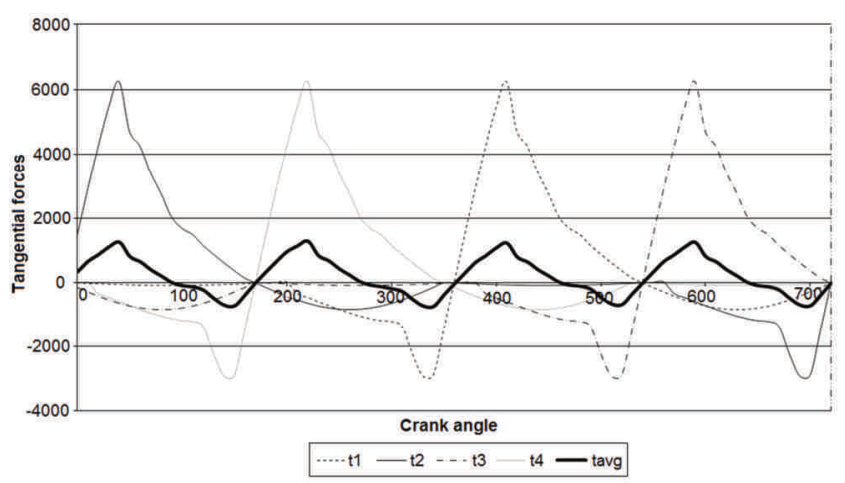

Fig. 3. The tangential force - no burning in four cylinders

\section{Equations of the electric starter circuit of the car}

Diagnostics is based on the analysis of the start and stop torque components of the engine. The equations describing the moment include the following.

The electric piston equation takes the form:

$$
E_{B}=\left(R_{a}+R_{B}\right) \cdot i_{a}(a)+\left(z_{a} \cdot \frac{\delta \phi_{t}}{\delta i_{t}}\right) \cdot \frac{d i_{t}}{d t}+c_{E} \cdot \phi_{a} \cdot \omega(a)
$$

where: $E_{B}$ - electromotive force unloaded battery [V], $R_{a}-$ resistance of the armature winding $[\Omega], R_{B}-$ internal resistance of the battery $[\Omega], \mathrm{d} \Psi_{\mathrm{a}} / \mathrm{dt}$ - voltage induced in the armature windings $[\mathrm{V}], \mathrm{i}_{\mathrm{a}}$ - current of the armature $[\mathrm{A}], \mathrm{z}_{\mathrm{a}}-$ number of coil windings of the armature, $\phi_{\mathrm{a}}-$ main magnetic flux of the armature circuit [Wb].

The mechanical system consisting of a starter rotor, gear and crankshaft has one degree of freedom. Therefore it is possible to describe it in one equation by reducing all the forces and moments to the axis of the starter rotor. The basis for determining the form of the equation is Formula 8, resulting from the principle of the conservation of mechanical energy:

$$
\frac{\mathrm{dE}}{\mathrm{dt}} \mathrm{A}=\mathrm{N}
$$

$\mathrm{E}$ - mechanical energy of the whole system, $\mathrm{N}$ - the resulting power of the driving and thrust forces

$$
\begin{gathered}
\mathrm{E}=\frac{\mathrm{I} \omega_{\mathrm{r}}^{2}}{2} \\
\mathrm{~N}=\mathrm{M} \cdot \omega_{\mathrm{r}}
\end{gathered}
$$

where: I - the incident moment of inertia of all the masses in motion reduced to the starter axis, $\mathrm{M}$ - the resulting 
torque of the drive and thrust forces reduced on the starter axis

$$
\frac{\mathrm{d}}{\mathrm{dt}}\left(\frac{\mathrm{I} \omega_{\mathrm{r}}^{2}}{2}\right)=\mathrm{M} \cdot \omega_{\mathrm{r}}
$$

or:

$$
\frac{d \mathrm{I}}{\mathrm{d} \varphi_{\mathrm{r}}} \cdot \frac{\omega_{\mathrm{r}}^{2}}{2}+\frac{\mathrm{d} \omega_{\mathrm{r}}}{\mathrm{dt}} \cdot \mathrm{I}=\mathrm{M}_{\mathrm{e}}+\mathrm{M}_{\mathrm{a}-\mathrm{t}}+\mathrm{M}_{\text {loss }}
$$

$\mathrm{M}_{\mathrm{e}}$ - magnetic moment produced in the starter, $\mathrm{M}_{\mathrm{a}-\mathrm{t}}$ - engine torque, reduced to the starter axis, $\mathrm{M}_{\text {loss }}-$ moment of mechanical and magnetic losses of the starter, $\varphi_{\mathrm{r}}-$ angle of rotation of the starter rotor.

A system of differential equations (12), describing at any time the process of starting a combustion engine:

$$
\left\{\begin{array}{c}
\frac{d \varphi_{r}}{d t}=\omega_{r} \\
\frac{d i}{d t}=\frac{U_{0}-k i-i R-c \omega_{r} \phi_{a}}{z_{a} \frac{\delta \phi_{a}}{\delta i}+z_{w} \frac{\delta \phi_{w}}{\delta i}} \\
\frac{d \omega_{r}}{d t}=\frac{c \phi_{a} i-M_{a-t}-M_{\text {loss }}-\frac{\omega_{r}}{2} \frac{d I}{d \varphi_{r}}}{I\left(\varphi_{r}\right)}
\end{array}\right.
$$

Assuming that: $\phi_{\mathrm{r}}=\mathrm{y}_{1}, \mathrm{i}=\mathrm{y}_{2}, \omega_{\mathrm{r}}=\mathrm{y}_{3}$

$$
\left\{\begin{array}{c}
\frac{d y_{1}}{d t}=y_{3} \\
\frac{d y_{2}}{d t}=\frac{U_{0}-k y_{2}-R\left(y_{2}, T\right)-c y_{3} \phi_{a}\left(y_{3}\right)}{z_{a} d \phi_{a}\left(y_{2}\right)+z_{w} d \phi_{m}\left(y_{2}\right)} \\
\frac{d y_{3}}{d t}=\frac{c \phi_{t}\left(y_{2}\right) y_{2}-M_{a-t}\left(y_{3}, y_{1}, T\right)-\frac{y_{3}{ }^{2}}{2} \cdot \frac{d l\left(y_{1}\right)}{d y_{1}}-M_{\text {loss }}\left(y_{3}, y_{2}\right)}{I\left(\varphi_{r}\right)}
\end{array}\right.
$$

In order to solve the system of differential equations, a program was written in the Matlab environment, on the basis of which the angular velocity, magnetic flux and current waveforms were derived, as shown in Fig. 5.

In this study, the current drawn by the starter during power-up is analysed. The simulation of the current flow on the PC is similar to that obtained from direct measurements. Using the data obtained from the above program regarding the starting current as a function of time, the curve $I=f(t)$ was analysed. After feeding the data into "starter.exe.", waveforms were plotted. Figure 4 shows the value of current changes during start-up obtained by computer simulation. The first part of the chart, which represents the maximum current increase (Fig. 6), deserves special attention.

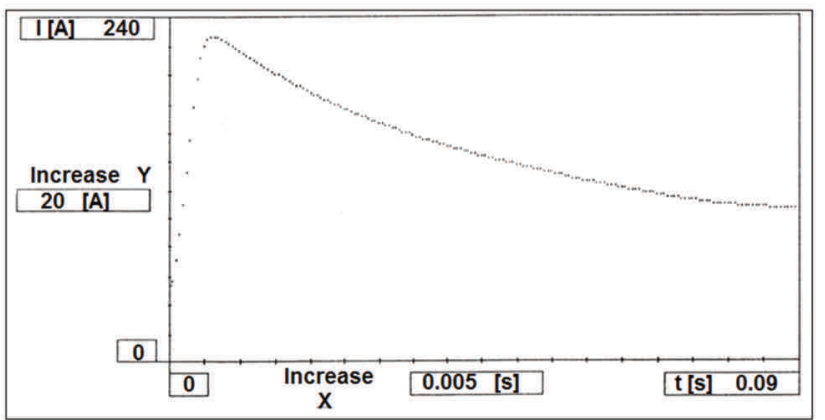

Fig. 4. Graph of the current drawn by the starter as a function of time

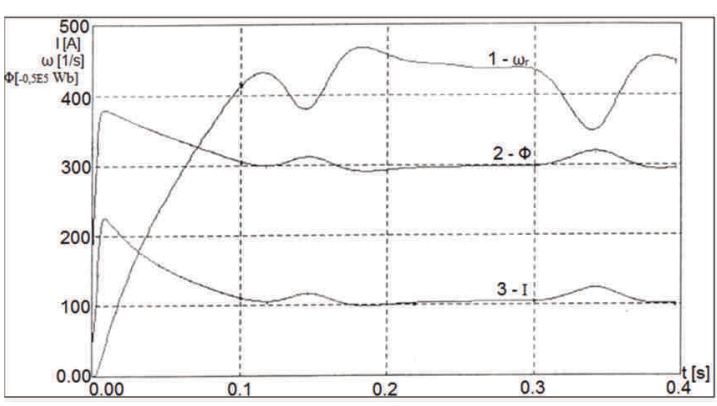

Fig. 5. Solution of the system of differential equations ( $1-$ angular velocity, 2 - magnetic flux, 3 - current waveform)

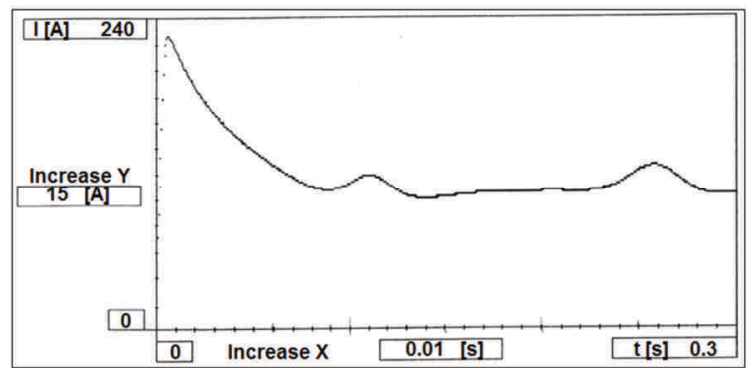

Fig. 6. Initial start-up phase

With a function that approximates the starting current, a definite integral can be calculated in the time interval of 0 $0.09 \mathrm{~s}$. The starting current size can be a characteristic parameter for various starter faults, as confirmed in the research part of the work.

\section{Modelling the characteristics of the starting current in Matlab}

The analysed system of first order differential equations was discretised, and then decoded numerically by means of the fourth-order Runge-Kutta method with the integration step. This method is commonly considered to be effective and corresponds to a compromise between the accuracy of solutions and the time of numeral simulations. In this case, the method was implemented in the Matlab environment.

A program was written that allows modelling current consumption by the starter for the engine's variable antitorque. The program includes equations describing antitorque in a four-cylinder internal combustion engine.

A characterisation of the starting current is shown in Fig. 7.

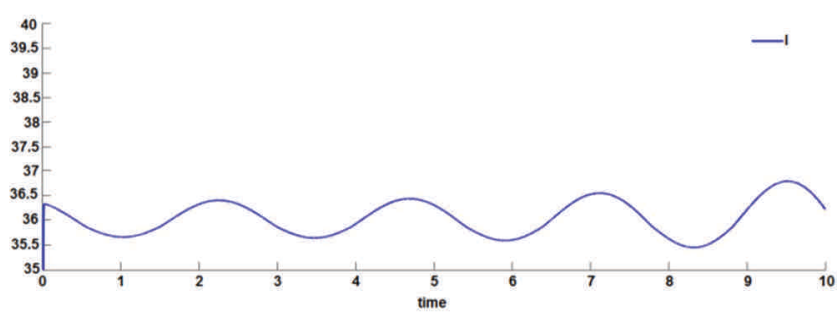

Fig. 7. Starting current characterisation for a four-cylinder engine

\section{Experimental verification tests}

In experimental research, the size of the starter circuit was measured using the BOSCH FSA 740 apparatus. Using the FSA device, the starting current measurements and indirect pressure measurements in individual cylinders 
(relative compression) were performed. The results of the measurements are shown in Figures 8-13.

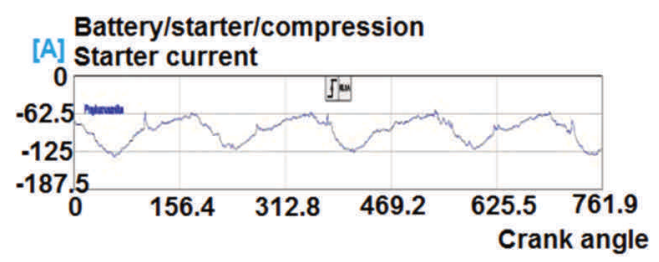

Fig. 8. Starting current for all spark plugs

Battery/starter/compression

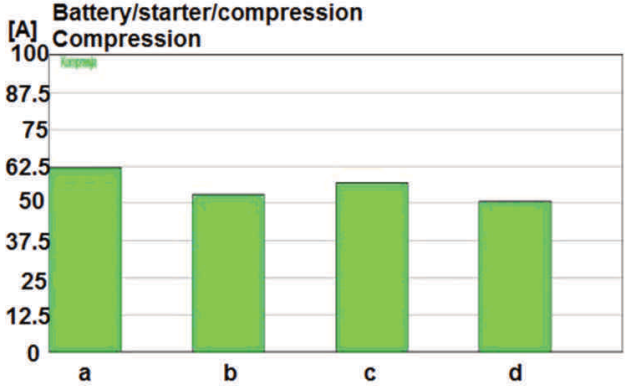

Fig. 9. Relative compression for all spark plugs

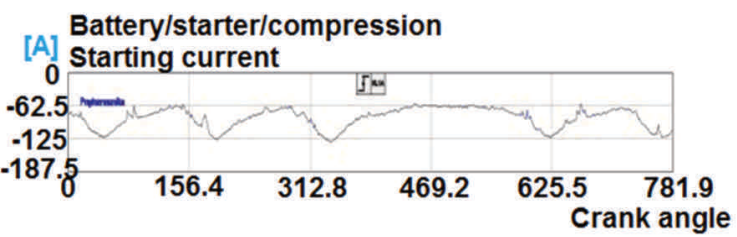

Fig. 10. Starting current with one spark plug removed

Battery/starter/compression

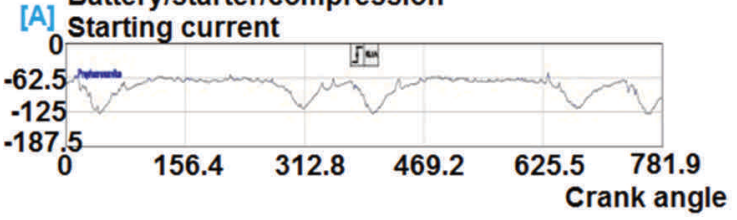

Battery/starter/compression

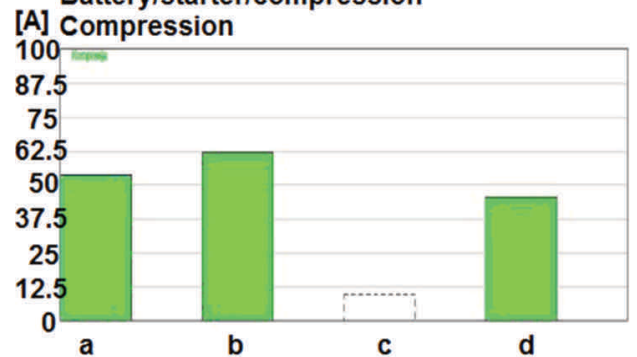

Fig. 11 Relative compression for one spark plug current for two spark plugs

Battery/starter/compression

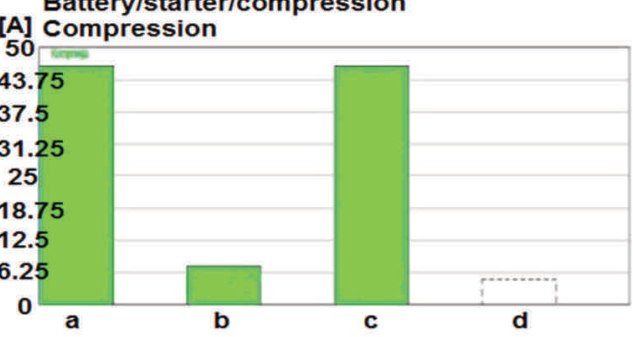

Fig. 13. Relative compression for two spark plugs

\section{Summary}

Analysis of the effect of starter failure can correct the indirect pressure measurement of the compression. Experimental research has allowed the results to be verified from the model thanks to the simulated changes in the tightness of the individual cylinders.

The registered starting current for one spark plug was confirmed by the absence of compression pressure in the unsealed cylinder. When two cylinders are unsealed, there is a change in the starting current, which confirms change of the torque in individual cylinders.

Fig. 12. Starting current for two spark plugs

\section{Nomenclature}

CI compression ignition

CNG compressed natural gas

DI direct injection
LPG liquified petrolum gas

SI spark ignition

\section{Bibliography}

[1] BAY, O., BAYIR, R. A fault diagnosis of engine starting system via starter motors using fuzzy logic algorithm. Gazi Journal University of Science. 2011, 24(3), 437-440.

[2] BURCAN, J., SICZEK K. The durability and reliability of bearing of car starter. Tribology. 2003, 4, 69-78.

[3] DUDZIKOWSKI, I., JANISZEWSKI, S. Analysis of car rmanent-magnet starters. Scientific Papers of The Institute of Electrical Machines, Drives and Measurements of the Wroctaw University of Science and Technology Series: Studies and Research. 2000, 20, 167-174.
[4] DZIUBIŃSKI, M., DROZD, A., ADAMIEC, M., SIEMIONEK, E. Simulation tests of the starting system. Poznan University of Technology Academic Journals. Electrical Engineering. 2016, 88, 89-100.

[5] DZIUBIŃSKI, M. Modeling and experimental testing of starting system in means of transport. Monograph, Lublin University of Technology, ISBN 978-83-7947-205-5, Lublin 2016.

[6] EBRAHAMI, E., MOLLAZDADE, K. Intelligent fault classification of a tractor starter motor using vibration monitoring and adaptive neuro fuzzy inference system. InsightNon-Destructive Testing and Condition Monitoring. 2010, 52(10), 561-566. 
[7] FUVESI, V., KOVACS, E. Diagnoses of additive faults of serial wounded motor using artificial intelligence methods. Recent Innovations in Mechatronics. 2014, 1(1).

[8] GAD, S., PAWLAK, M. The artificial neural networks as the tool for diagnostics of automotive vehicles. Electrotechnical Review. 2004, 7(8), 693-697.

Mieczysław Dziubiński, DEng. - Faculty of Mechanical Engineering at Lublin University of Technology, Poland.

e-mail:m.dziubinski@pollub.pl

Arkadiusz Syta, DEng. - Faculty of Mechanical

Engineering at Lublin University of Technology, Poland.
[9] PSZCZÓŁKOWSKI, J., TRAWIŃSKI, G. Engine crankshaft driving with the help of electric and pneumatic starter. Logistics. 2011, 6, 3499-3508.

[10] ZENG, S., SUN, B., TONG, CH. A modified model of electronic device reliability protection. Maintenance and reliability. 2009, 4, 4-9.

Paweł Kordos, DEng. - Faculty of Mechanical Engineering at Lublin University of Technology,

Poland.

Artur Drozd, MEng. - Faculty of Mechanical Engineering at Lublin University of Technology, Poland. 